\begin{tabular}{cc|c}
\hline Tar. Bil. Der. & Journal of Agricultural Sciences \\
& $\begin{array}{c}\text { Dergi web sayfası: } \\
\text { www.agri.ankara.edu.tr/dergi }\end{array}$ & Journal homepage: \\
& www.agri.ankara.edu.tr/journal
\end{tabular}

\title{
Isparta Yöresinde Yă̆ Gülü Üretiminde Enerji Girdi Çıktı Analizi
}

\author{
Osman GÖKDOĞAN ${ }^{\mathrm{a}}$, Fikret DEMIR ${ }^{\mathrm{b}}$ \\ ${ }^{a}$ Hakkari Üniversitesi, Yüksekova Meslek Yüksekokulu, Hakkâri, TÜRKIYE \\ ${ }^{b}$ Selçuk Üniversitesi, Ziraat Fakültesi, Tarım Makinaları Bölümü, Konya, TÜRKIYYE
}

\section{ESER BILGISİ}

Araştırma Makalesi — Tarım Teknolojileri $\quad$ https://doi.org/10.1501/Tarimbil_0000001226

Sorumlu Yazar: Osman GÖKDOĞAN, E-posta: osmangokdogan@mynet.com, Tel: +90 (555) 5660834

Geliş Tarihi: 24 Aralık 2012, Düzeltmelerin Gelişi: 21 Şubat 2013, Kabul: 23 Nisan 2013

\begin{abstract}
ÖZET
Bu çalışmada, Isparta yöresindeki yağlık gül bitkisi yetiştiriciliğinde enerji bilançosunun belirlenmesi amaçlanmıştır. İşletmelerin seçiminde basit tesadüfi örnekleme yöntemi kullanılmıştır. Anket uygulanacak işletme sayısı 121 olarak belirlenmiştir. 2008 yılında 121 işletme ile yüz yüze anket yapılarak ön çalışma yapılmıştır. Enerji bilançosu çalışması; 121 işletme içerisinden seçilen 15 işletmede 2009 ve 2010 yıllarında yapılan gözlem ve ölçüm yoluyla gerçekleştirilmiştir. Araştırmada üretim faaliyetindeki etkinliğin ölçülmesinde parametrik olmayan VZA (Veri Zarflama Analizi) kullanılmıştır. Etkinlik ölçümlerinin tahmini, SPSS ve DEAP 2.10 paket programında yapılmıştır. Yağlık gül

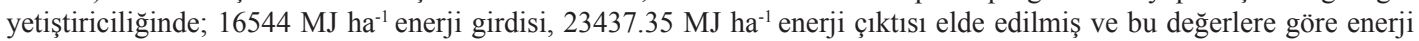
çıktı/girdi oranı 1.42 olarak bulunmuştur. Birinci ve ikinci yılın ortalama genel enerji girdileri içerisinde insan işgücü enerjisi, gübre enerji girdisinden sonra ikinci sırada yer almıştır. Bu durum, yağlık gül yetiştiriciliğinde mekanizasyonun özellikle de hasat mekanizasyonu uygulamalarının yetersiz olduğunu göstermektedir.
\end{abstract}

Anahtar Kelimeler: Enerji; Mekanizasyon düzeyi; Yağ gülü

\section{Energy Input-Output Analysis in Rose Oil Agriculture in Isparta Province}

\section{ARTICLE INFO}

Research Article - Agricultural Technologies

Corresponding Author: Osman GÖKDOĞAN, E-mail: osmangokdogan@mynet.com, Tel: +90 (555) 5660834

Received: 24 December 2012, Received in Revised Form: 21 February 2013, Accepted: 23 April 2013

\begin{abstract}
In this study, it was aimed to determine the energy balance in oil rose production in Isparta province in Turkey. Simple random sampling method was used in the selection of enterprises. The survey was applied to 121 the number of farms. In 2008, a preliminary study was done face to face interviews with 121 farms. Rose cultivation trials to determine the energy balance were discussed and the tests were performed in 15 plants. In 15 plants, energy balance sheets were also determinated by observation and measurement methods in 2009 and 2010. Non-parametric data envelopment analysis was used in the measurement of productive activity efficiency. Prediction of productive activity efficiency measurement
\end{abstract}


was made via SPSS and DEAP 2.10 pocket software. In cultivation of rose oil, it was determined that energy input was $16544 \mathrm{MJ} \mathrm{ha}^{-1}$, energy output was $23437.35 \mathrm{MJ} \mathrm{ha}^{-1}$ and output/input ratio 1.42. According the first and second years test results, it was found that the input energy of fertilizer was higher than the human labor energy input. This situation is due to inadequate practices oilseed harvest mechanization especially in the cultivation of roses.

Keywords: Energy; Mechanization level; Oil rose

(C) Ankara Üniversitesi Ziraat Fakültesi

\section{Giriş}

Gül tarımı, Göller Bölgesi'nde önemli bir yer tutmakta ve pek çok ailenin geçim kaynağ olmaktadır. Isparta yöresinde yaklaşık 8000 çiftçi ailesi gül üretimiyle uğraşmaktadır. Isparta'da gül üretim alanlarının toplam tarım alanı içerisindeki payı yaklaşık \% 1'dir. Ekonomik olarak yörenin elma ve kirazdan sonra önde gelen ana tarım ürünlerinden biridir (TBMM 2006). Gül çiçekleri işlenerek başlıca gülyağı, gül konkreti, gül absolütü, gülsuyu gibi güle dayalı farklı ürünler üretilmekte olup, yerli tüketim çok az olduğu için ihraç edilerek Türkiye ekonomisine katkı sağlamaktadır (İGEME 2003). Dünya gülyağı üretimi yaklaşık 4.50 ton, konkret üretimi ise 13 ton'dur. Türkiye, Dünya gülyağı üretiminin yaklaşık \% 48'ini, konkret üretiminin ise yaklaşık \% 39'unu karşılamaktadır (Kıneci 2005). Doğal parfüm hammaddeleri içinde en önemli yeri gülyağı, gül konkreti ve gül absolütü almaktadır. Gülyağı koku görevi yanında, kokunun tende veya herhangi bir cisimde kalmasını sağlar, tutkal görevini yaparak formülasyonda fiksatörlük (yapıştırıcılık) görevini yerine getirir (Shreve et al 1985).

Yılmaz (1991), yağlık gül yetiştiriciliği, işletmenin tesisinden-yetiştirmeye, yetiştirmedenhasada, hasattan-işlemeye ve işlemedenpazarlamaya kadar birçok sorunlarla karşı karşıya olduğunu, mevcut sorunlara çözüm aranmadıkça bu sektörün önemini kaybedeceğini ve Türk gülyağının Dünya pazarında rekabet gücünün ancak kaliteli gül yağı ile sağlanabileceğini ifade etmiştir. Türkiye'de yağ gülü üretimi ile ilgili çalışmalar az olup, genellikle gül yağının kimyasal özellikleri üzerinde yoğunlaşmıştır. Bu çalışmayla yağ gülü yetiştiriciliğinin enerji bilançosu belirlenmiştir.

\section{Materyal ve Yöntem}

\section{1. Örneklerin seçimi}

Denemeler, Isparta yöresinde gül tarımının yapıldığı Merkez ilçe ile Atabey, Gönen ve Keçiborlu ilçelerine bağlı 11 köyde (İslamköy, Harmanören, Güneykent, Gümüşgün, İğdecik, Kılıç, Senir, Aliköy, Deregümü, Kayıköy ve Yakaören) yapılmıştır. Denemelerin yürütüldüğü 11 köyde bulunan 121 tarımsal işletmeye anket çalışması yapılmıştır. Daha sonra 2009 ve 2010 yıllarında 15 işletmede enerji bilançosunun belirlenmesi için çalışmalar yürütülmüştür.

\subsection{Araştırmada kullanılan alet ve cihazlar}

Gül çiçeklerinin nem oranlarının belirlenmesi için $0.001 \mathrm{~g}$ hassasiyetinde ölçüm yapabilen $310 \mathrm{~g}$ kapasiteli KERN PLE marka hassas terazi gerekli tartımlarda kullanılmıştır. Gül yapraklarının enerji eşdeğerini belirleme işlemi IKA marka, ölçüm aralığı 40000 J'e kadar olan kalorimetre cihazı ile yapılmıştır. Tarımsal işlemlerin zaman ölçümleri Hanhart 7 Jewels Shockproof marka, $0.10 \mathrm{~s}$ hassasiyetli kronometre ile gerçekleştirilmiştir. Gül çiçeklerinin nem seviyelerinin belirlenmesi için gerekli kurutma işlemi Nüve FM 500 marka etüvde gerçekleştirilmiştir. İşletmelerin seçiminde aşağıda verilen basit tesadüfi örnekleme yöntemi kullanılmıştır (Çiçek \& Erkan 1996).

$$
n=\frac{N \times S^{2} \times t^{2}}{(N-1) d^{2}+\left(S^{2} \times t^{2}\right)}
$$

Bu eşitlikte; n, örnek sayısı; $S$, populasyon varyansı; $\mathrm{N}$, populasyonu oluşturan işletme sayısı; $\mathrm{t}$, standart normal dağılım değeri ve $\mathrm{d}$, populasyona ait hata terimidir. 
Populasyondan, örnekleme çerçevesinin oluşturulmasında $\% 5$ hatapayıve $\% 95$ güven sınırları içerisinde çalışılmıştır. Eşitliğin kullanılmasıyla uygulama ve çalışma alanını karakterize edecek işletme sayısı 121 olarak belirlenmiştir. 2008 yılında 121 işletme ile yüz yüze anket yapılarak ön çalışma yapılmıştır. Gül tarımının enerji bilançosunu belirlemek için denemelerin yapılabileceği 15 adet işletme ele alınmış ve denemeler bu işletmelerde yapılmıştır. Enerji bilançosu çalışması, seçilen 15 işletmede 2009 ve 2010 yıllarında yapılan gözlem ve ölçüm yoluyla gerçekleştirilmiştir.

\section{3. Çalışma hızının belirlenmesi}

Kronometre yardımıyla parsel boyunca tarımsal işlemler sırasında geçen zaman ölçülmüş, işlenen alandaki parsel uzunluğundan yararlanarak aşağıdaki eşitlik yardımıyla gerçek ilerleme hızı belirlenmiştir (Sonmete 2006).

$$
V_{g}=3.60 \frac{L}{t}
$$

Burada; $V_{g}$, gerçek ilerleme hızı $\left(\mathrm{km} \mathrm{h}^{-1}\right) ; L$, ölçüm uzunluğu (m) ve $t$, ölçüm uzunluğunun alınması için geçen zamanların aritmetik ortalamasıdır (s).

\subsection{Yaknt tüketiminin belirlenmesi}

Yakıt tüketiminin belirlenmesinde dolu depo yönteminden yararlanılmıştır. Çalışmaya başlamadan önce traktörün yakıt deposu tamamen doldurulmuştur. Çalışma sonunda ise ölçekli kap kullanılarak, depo tekrar ilk seviyesine kadar doldurulmuştur. İşlem yapılan alan ve doldurulan yakıt miktarı ölçülerek birim alan için tüketilen yakıt miktarı belirlenmiştir (Göktürk 1999; El Saleh 2000).

\subsection{Zaman etüdü ve efektif alan iş başarısı}

Güzel (1986) ve Özcan (1986)'a göre; zaman ölçümleri ve alan iş verimi hesaplamalarında üçlü kronometre ölçüm seti kullanılmıştır. İş başarısı, efektif alan iş başarısı olarak belirlenmiştir. Deneme parselleri işlenirken efektif çalışma zamanı $\left(\mathrm{T}_{\text {ef }}\right)$ kullanılarak iş verimi $\left(\mathrm{ha} \mathrm{h}^{-1}\right)$ olarak hesaplanmıştır (Sonmete 2006).

$$
A_{\text {is }}=0.10 \times B_{g} \times V_{g} \times T_{e f}
$$

$T_{e f}=\frac{T_{e s}}{\left(T_{e s}+T_{d}+T_{k}\right)}$

Burada; $A_{i, s}$, iş başarısı (ha $\left.\mathrm{h}^{-1}\right) ; B_{g}$, gerçek iş genişliği (m); $V_{g}$, gerçek ilerleme hızı $\left(\mathrm{km} \mathrm{h}^{-1}\right) ; T_{e f}$, zamandan yararlanma katsayısı $(\%) ; T_{e s}$, esas zaman $(\mathrm{h}) ; T_{d}$, dönme zamanı (h); $T_{k}$, kayıp zamandır(h).

\subsection{Makine yapım enerjisinin belirlenmesi}

Makine yapım enerjisinin belirlenmesinde aşağıdaki eşitlikten yararlanılmış ve gül tarımında kullanılan makinelerin, makine yapım enerjileri ayrı ayrı hesaplanmıştır (Heyland \& Solansky 1979; Gezer et al 2003; Sonmete 2006).

$M_{p}=0.82 \times\left(M_{\ddot{u}}+F\right)+Y_{d}$

Burada; $M_{p}$, makine yapım (imalat) enerjisi (MJ); $M_{i}$, malzeme üretim enerjisi (MJ); $F$, fabrika yapım enerjisi olup makinanın toplam kütlesi ile fabrika yapım katsayısının çarpılmasıyla elde edilir (MJ). $Y_{d}$, yedek parça enerjisidir (MJ).

Yukarıdaki formüle göre bulunan değerler, makinenin kütlesi, makinenin ekonomik ömrü ve iş başarısı dikkate alınarak birim alan başına düşen enerji girdileri bulunmuştur (Heyland \& Solansky 1979). Makine enerjisi Türkiye demir çelik endüstrisi şartlarına göre aşağıdaki eşitlik kullanılarak ayrı ayrı hesaplanmıştır (Acaroğlu 1998).

$M_{p e}=\frac{\left(G \times M_{p}\right)}{\left(T \times A_{i \varsigma}\right)}$

Burada; $M_{p e}$, birim alan başına düşen makine enerjisi $\left(\mathrm{MJ} \mathrm{ha}^{-1}\right) ; G$, makinenin kütlesi ( $\left.\mathrm{kg}\right) ; M_{p}$, makine yapım (imalat) enerjisi $\left(\mathrm{MJ} \mathrm{kg}^{-1}\right)$; $\mathrm{T}$, makinenin kullanım

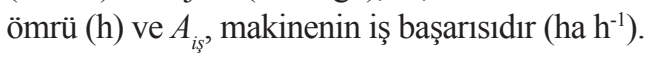

Gülün enerji eş değerinin belirlenmesi için rastgele seçilen gül yaprakları kalorimetre cihazında, üç tekerrürlü yakılarak enerji değeri bulunmuştur. İki yıl yürütülen tarla denemelerinde, işletmelerdeki gül hasadındaki çalışmalar her yıl 30 gün süresince yapılmıştır. Hasat günlerinde rastgele seçilen gül yapraklarının nem seviyeleri etüvde, AOAC (1999)'a göre,135 ${ }^{\circ} \mathrm{C}$ 'de yaklaşık olarak 2 saat süreyle, sabit tartıma gelinceye kadar kurutulmuştur Böylece kurutulan gül örneklerinin kuru madde oranları belirlenmiştir. 


\subsection{Enerji bilançolarının belirlenmesi}

Isparta yöresindeki gül işletmelerinin, yapılan denemeler ve ölçümler sonucunda, enerji girdi ve çıktı değerleri belirlenmiştir. Enerji girdileri olarak traktör yapım enerjisi, makine yapım enerjisi, yakıtyağ enerjisi, gübre enerjisi, tarımsal ilaç enerjisi, sulama enerjisi, insan işgücü enerjisi ve taşıma enerjisi değerleri dikkate alınmıştır. İki yılda alınan örneklerden kuru madde miktarı belirlenerek elde edilen \%17 kuru madde değeri kullanılmıştır.

Yağlık gül üretiminde enerji kullanım etkinliğini belirlemek amacıyla, enerji çıktı/girdi oranı aşağıdaki formülle hesaplanmıştır (Mandal et al 2002; Singh et al 1997).

$$
\frac{C_{1} k t 1}{\text { Girdi }}=\frac{C_{1} \text { kan Enerji }\left(\frac{M J}{h a}\right)}{\text { Giren Enerji }\left(\frac{M J}{h a}\right)}
$$

\subsection{Sonuçların değerlendirilmesi}

Çiftçiler çıktılardan daha çok girdileri kontrol etme konumunda olduklarından, bu araştırmada Farrell (1957)'in girdiye yönelik etkinlik ölçümleri kullanılmış olup, çok girdili-tek çıktılı bir model oluşturulmuştur. Etkinlik ölçümlerinin tahmini, SPSS ve Coelli (1996) tarafından geliştirilmiş DEAP 2.10 paket programında yapılmıştır. İşletmelerin üretim etkinliğini ortaya koymak amaciyla, parametrik olmayan bir yöntem olan VZA kullanılmıştır. VZA yapılırken özel bir üretim fonksiyonuna ihtiyaç duyulmamaktadır. İkinci neden ise etkinliğin ölçüsü olarak kabul edilen hata terimine ait dağılım tipinin önceden belirlenmesi gerekmemektedir (Coelli et al 2002). Bu nedenle araştırmada söz konusu üretim faaliyetinde etkinliğin ölçülmesinde parametrik olmayan VZA kullanılmıştır. Tarımsal üretimde kullanılan girdi ve çıktıların enerji eşdeğerleri Çizelge 1'de verilmiştir.

\section{Çizelge 1- Tarımsal üretimde girdi ve çıktıların enerji eşdeğerleri}

Table 1- Energy equivalents of inputs and outputs in agricultural production

\begin{tabular}{|c|c|c|c|}
\hline Girdiler ve çıtılar & Birimi & Enerji eşdeğeri katsayısı & Kaynaklar \\
\hline Girdiler & Birimi & Değerler $\left(\mathrm{MJ}\right.$ birim $\left.^{-1}\right)$ & Kaynaklar \\
\hline $\begin{array}{l}\text { İnsan işgücü } \\
\text { Gübreler }\end{array}$ & $\mathrm{h}$ & 1.87 & Kaltschmitt \& Reinhardt 1997* \\
\hline $\mathrm{P}_{2} \mathrm{O}_{5}$ & $\mathrm{~kg}$ & 15.18 & Kaltschmitt \& Reinhardt 1997 \\
\hline $\mathrm{N}^{2}$ & $\mathrm{~kg}$ & 47.10 & Kaltschmitt \& Reinhardt 1997 \\
\hline Çiftlik gübresi & $\mathrm{kg}$ & 0.30 & Singh 2002 \\
\hline Tarımsal ilaç & $\mathrm{kg}$ & 101.20 & Önal \& Tozan 1986 \\
\hline Girdiler & Birimi & Değerler $\left(\mathrm{MJ}\right.$ birim $\left.^{-1}\right)$ & Kaynaklar \\
\hline Traktör & $\mathrm{kg}$ & 71.38 & - \\
\hline Kulaklı pulluk & $\mathrm{kg}$ & 49.36 & - \\
\hline Kültivatör & $\mathrm{kg}$ & 49.36 & - \\
\hline Goble disk & $\mathrm{kg}$ & 49.36 & - \\
\hline Toprak frezesi & $\mathrm{kg}$ & 49.36 & - \\
\hline Pülverizatör & $\mathrm{kg}$ & 102.26 & - \\
\hline Girdiler & Birimi & Değerler (Birim) & Kaynaklar \\
\hline Traktör & $\mathrm{h}$ & 10000 (Ömür) & Dinçer 1976 \\
\hline Taşıma & $\mathrm{MJ} \mathrm{t}^{-1} \mathrm{~km}^{-1}$ & 9.22 & Acaroğlu 2004** \\
\hline Kulaklı pulluk & $\mathrm{h}$ & 2300 (Ömür) & Yildiz et al 2006 \\
\hline Kültivatör & $\mathrm{h}$ & 2500 (Ömür) & Hacıseferoğulları et al 2003 \\
\hline Pülverizatör & $\mathrm{h}$ & 750 (Ömür) & Yildiz et al 2006 \\
\hline Girdiler & Birimi & Değerler $\left(\mathrm{MJ}\right.$ birim $\left.^{-1}\right)$ & Kaynaklar \\
\hline Diesel & $\mathrm{L}$ & 40.035 & Kaltschmitt \& Reinhardt 1997 \\
\hline Sulama suyu & $\mathrm{m}^{3}$ & 2.93 & Çalışır 2004 \\
\hline Çıktılar & Birimi & Enerji eşdeğeri katsayısı & Kaynaklar \\
\hline Çıktılar & Birimi & Değerler $\left(\mathrm{MJ} \mathrm{birim}^{-1}\right)$ & Kaynaklar \\
\hline Gül çiçeği & MJ (kg kuru madde) $)^{-1}$ & 20.22 & - \\
\hline
\end{tabular}




\section{Bulgular ve Tartışma}

\subsection{Gül üretiminde enerji bilançosu}

Araştırmanın ilk yılında, denemelerin yürütüldüğü 15 işletmeye ait, ortalama mekanizasyon ile gübre ve kimyasal enerji girdileri Çizelge 2 ve 3 'de, ortalama genel enerji girdileri ile çıkt1/girdi oranları ise Çizelge 4 ve 5' de verilmiştir.

İlk y1l yürütülen tarla denemelerinde, 15 işletmeye ait ortalama enerji girdileri içerisinde insan işgücünün, mekanizasyon girdilerinin kullanımında yer alması ve özellikle 30 gün süren hasat işleminde hasatta mekanizasyon olmadığı için bunun yerine tamamıla insan işgücünün kullanılması neticesinde ilk sırayı \% 73.99 oranı ile insan işgücünün aldığı görülmektedir. Bunu \% 19.56 ile yakıt-yağ enerji girdisi, \% 3.23 ile traktör yapım enerjisi ve \% 3.22 ile makine yapım enerjisi girdileri izlemektedir (Çizelge 2).

Tarımsal işletmelerin ortalama gübre enerji girdisi değeri $9370.08 \mathrm{MJ} \mathrm{ha}^{-1}$, çiftlik gübresi enerji girdisi değeri $500 \mathrm{MJ} \mathrm{ha}^{-1}$ ve kullanılan tarımsal ilaç girdi enerjisi değeri ise $715.48 \mathrm{MJ} \mathrm{ha}^{-1}$ olarak belirlenmiş̧ir (Çizelge 3). Denemelerin ilk yılında elde edilen ortalama genel enerji girdileri içerisinde $\%$ 56.99'luk oranla gübre enerji girdisi ilk sirada yer almaktadır. Bunu \% 25.70'lik oranla işgücü enerji girdisi, \% 6.79'luk oranla yakıt-yağ enerjisi ve \% 4.35'lik oranla kullanılan tarımsal ilaçların enerji girdisi izlemektedir (Çizelge 4). Traktör, makine, sulama, çiftlik gübresi ve taşıma enerji girdilerinin oranlarının ise düşük değerlerde kaldığı Çizelge 4'de görülmektedir. Çizelge 5'de ise çıktı girdi değerleri verilmiştir.

Çizelge 2- Denemelerin ilk yllında elde edilen ortalama mekanizasyon enerji girdileri

Table 2-In the first experiments the mean mechanization energy inputs

\begin{tabular}{|c|c|c|c|c|c|}
\hline $\begin{array}{l}\text { Tarımsal } \\
\text { işlem }\end{array}$ & $\begin{array}{c}\text { Traktör yapım enerjisi } \\
\left(M J \mathrm{Ma}^{-1}\right)\end{array}$ & $\begin{array}{c}\text { Makine yapım enerjisi } \\
\left(M J \mathrm{ha}^{-1}\right)\end{array}$ & $\begin{array}{l}\text { Yakıt-yă̆ enerjisi } \\
\left(M J h a^{-1}\right)\end{array}$ & $\begin{array}{l}\text { İsgücü enerjisi } \\
\left(M J h a^{-1}\right)\end{array}$ & $\begin{array}{l}\text { Toplam } \\
\left(\text { MJ ha }^{-1}\right)\end{array}$ \\
\hline $\begin{array}{l}\text { Traktör } \\
\left(\mathrm{MJ} \mathrm{h}^{-1}\right)\end{array}$ & 27.78 & - & - & - & - \\
\hline $\begin{array}{l}\text { Toprak } \\
\text { işleme }\end{array}$ & 74.37 & 16.23 & 834.06 & 5.10 & 929.76 \\
\hline Çapalama & - & - & - & 98.49 & 98.49 \\
\hline Budama* & - & - & 21.31 & 84.03 & 105.34 \\
\hline Gübreleme & - & - & - & 31.17 & 31.17 \\
\hline İlaçlama & 109.78 & 167.90 & 261.56 & 16.81 & 556.05 \\
\hline Sulama & - & - & - & 1.81 & 1.81 \\
\hline Hasat & - & - & - & 3986.84 & 3986.84 \\
\hline Toplam & 184.15 & 184.13 & 1116.93 & 4224.25 & 5709.46 \\
\hline Dağılım (\%) & 3.23 & 3.22 & 19.56 & 73.99 & 100 \\
\hline
\end{tabular}

*Budama işlemi, insan işgücü ile kullanılan, yakıt-yağ ile çalışan odun kesme motorları ile yapılmıştır.

Çizelge 3- Denemelerin ilk yılında elde edilen ortalama gübre ve tarımsal ilaçların enerji girdileri

Table 3-In the first experiments the mean energy inputs of fertilizers and pesticides

\begin{tabular}{|c|c|c|c|}
\hline Girdiler & Miktarl $\left(\mathrm{kg} \mathrm{ha}^{-1}\right)$ & Enerji eşdeğeri $\left(\mathrm{MJ} \mathrm{kg}^{-1}\right)$ & $M J h a^{-1}$ \\
\hline Gübre N & 117.40 & 47.10 & 5529.54 \\
\hline \multirow[t]{2}{*}{ Gübre P } & 253 & 15.18 & 3840.54 \\
\hline & & Toplam gübre enerjisi & 9370.08 \\
\hline Çiftlik gübresi & 1666.67 & 0.30 & 500 \\
\hline Tarımsal ilaç & 7.07 & 101.20 & 715.48 \\
\hline
\end{tabular}


Çizelge 4- Denemelerin ilk yılında elde edilen ortalama genel enerji girdileri ve dağılımları

Table 4- In the first experiments the mean overall energy inputs and distributions

\begin{tabular}{lcc}
\hline Enerji girdileri & $M J h^{-1}$ & Dă̆llım (\%) \\
\hline Yakıt-yağ enerjisi & 1116.93 & 6.79 \\
Traktör enerjisi & 184.15 & 1.12 \\
Makine enerjisi & 184.13 & 1.12 \\
İşü̈cü enerjisi & 4224.25 & 25.70 \\
Sulama enerjisi & 60.55 & 0.37 \\
Tarımsal ilaç & 715.48 & 4.35 \\
Gübre enerjisi & 9370.08 & 56.99 \\
(Mineral gübre enerjisi) & 500.00 & 3.04 \\
Çiftlik gübresi enerjisi & 85.82 & 0.52 \\
Taşıma enerjisi & 16441.39 & 100 \\
\hline Toplam & & \\
\hline
\end{tabular}

Çizelge 5- Denemelerin ilk yılında elde edilen ortalama çıktı ve girdi değerleri

Table 5-Output and input values obtained from the average of the first year of trials

\begin{tabular}{cc}
\hline Toplam girdi $\left(\mathrm{MJ} \mathrm{ha}^{-1}\right)$ & Toplam çıktı $\left(\mathrm{MJ} \mathrm{ha}^{-1}\right)$ \\
\hline 16441.39 & 23271.20 \\
\hline
\end{tabular}

Isparta yöresinde yağlık gül üretimi yapan tarımsal işletmelerin ikinci yıl denemelerinde elde edilen ortalama mekanizasyon, gübre ve kimyasal enerji girdileri Çizelge 6 ve 7'de, ortalama genel enerji girdileri ile çıktı/girdi oranları ise Çizelge 8 ve 9'da verilmiştir.

\section{Çizelge 6- Denemelerin ikinci yılında elde edilen ortalama enerji girdileri}

Table 6- Energy inputs per second obtained in experiments

\begin{tabular}{|c|c|c|c|c|c|}
\hline Tarımsal işlem & $\begin{array}{c}\text { Traktör } \\
\left(M J h a^{-1}\right)\end{array}$ & $\begin{array}{l}\text { Makine } \\
\left(M J h a^{-1}\right)\end{array}$ & $\begin{array}{l}\text { Yakıt-yă } \\
\left(M J h a^{-1}\right)\end{array}$ & $\begin{array}{l}\text { İşgücü } \\
\left(M J h a^{-1}\right)\end{array}$ & $\begin{array}{c}\text { Toplam } \\
\left(M^{\prime} h a^{-1}\right)\end{array}$ \\
\hline Traktör $\left(\mathrm{MJ} \mathrm{h}^{-1}\right)$ & 27.78 & - & - & - & - \\
\hline Toprak işleme & 70.98 & 15.70 & 822.05 & 4.88 & 913.61 \\
\hline Çapalama & - & - & - & 109.70 & 109.70 \\
\hline Budama* & - & - & - & 102.65 & 102.65 \\
\hline Gübreleme & - & - & - & 32.72 & 32.72 \\
\hline İlaçlama & 111.30 & 166.88 & 232.06 & 25.97 & 536.21 \\
\hline Sulama & - & - & - & 1.49 & 1.49 \\
\hline Hasat & - & - & - & 3822.28 & 3822.28 \\
\hline Toplam & 182.28 & 182.58 & 1054.11 & 4099.69 & 5518.66 \\
\hline Dağılım (\%) & 3.30 & 3.31 & 19.10 & 74.29 & 100 \\
\hline
\end{tabular}

*Budama işlemi insan işgücü ile kullanılan çift el dal budama makasları ile yapılmıştır. 
Çizelge 7- Denemelerin ikinci yılında elde edilen ortalama gübre ve tarımsal ilaçların enerji girdileri

Table 7-In the second year of trials the mean energy inputs of fertilizers and pesticides

\begin{tabular}{lccc}
\hline Girdiler & Miktarı $\left(\mathrm{kg} \mathrm{ha}^{-1}\right)$ & Enerji eşdeğeri $\left(\mathrm{MJ} \mathrm{kg}^{-1}\right)$ & MJ ha $^{-1}$ \\
\hline Gübre N & 125 & 47.10 & 5887.50 \\
Gübre P & 253 & 15.18 & 3840.54 \\
\hline & & Toplam gübre enerjisi & 9728.04 \\
\hline Çiftlik gübresi & 1666.67 & 0.30 & 500 \\
\hline Tarımsal ilaç & 7.40 & 101.20 & 748.88 \\
\hline
\end{tabular}

Çizelge 6'da görüldüğü gibi, yağlık gül üretimi yapan işletmelerin ikinci yıl yapılan tarla denemelerinde ortalama enerji girdileri içerisinde ilk sırayı \% 74.29 oran ile insan işgücü enerji girdisinin oluşturduğu görülmektedir. Bunu \% 19.10 ile yakıt-yağ enerji girdisi, \% 3.31 ve \% 3.30'luk oranları ile makine ve traktör yapım enerji girdileri izlemektedir. İkinci yıl denemelerinde, toplam gübre enerji girdisi değeri $9728.04 \mathrm{MJ} \mathrm{ha}^{-1}$, çiftlik gübresi enerji girdi değeri $500 \mathrm{MJ} \mathrm{ha}^{-1}$ ve kullanılan kimyasal ilaç girdi enerji değeri ise $748.88 \mathrm{MJ} \mathrm{ha}^{-1}$ olarak belirlenmiştir (Çizelge 7).
Denemelerin ikinci y1lında elde edilen ortalama genel enerji girdileri içerisinde \% 58.45'lik oranla gübre enerji girdisi ilk sırada yer almaktadır. Bunu \% 24.63'lük oranla işgücü enerji girdisi, \% 6.33'lük oranla yakıt-yağ enerjisi ve \% 4.50'lik oranla kullanılan kimyasal ilaçların enerji girdisi oluşturmaktadır. Traktör, makine, sulama, çiftlik gübresi ve taşıma enerji girdilerinin oranlarının ise düşük değerlerde kaldığı Çizelge 8'de görülmektedir. Çizelge 9'da çıktı girdi değerleri verilmiştir.

Çizelge 8- Denemelerin ikinci yılında elde edilen ortalama genel enerji girdileri ve dağılımları

Table 8-In the second year of trials and the distribution of the mean overall energy inputs

\begin{tabular}{lcc}
\hline Enerji girdileri & $M J \mathrm{~h}^{-1}$ & Dă̆gllm (\%) \\
\hline Yakıt-yă̆ enerjisi & 1054.11 & 6.33 \\
Traktör enerjisi & 182.28 & 1.09 \\
Makine enerjisi & 182.58 & 1.09 \\
İşgücü enerjisi & 4099.69 & 24.63 \\
Sulama enerjisi & 66.41 & 0.40 \\
Tarımsal ilaç & 748.88 & 4.50 \\
Gübre enerjisi & 9728.04 & 58.45 \\
(Mineral gübre enerjisi) & 500 & 3.00 \\
Çiftlik gübresi enerjisi & 84.62 & 0.51 \\
Taşıma enerjisi & 16646.61 & 100 \\
\hline Toplam & &
\end{tabular}

Çizelge 9- Denemelerin ikinci yılında elde edilen ortalama çıktı girdi değerleri

Table 9- Output and input values obtained from the average of the second year of trials

\begin{tabular}{cc}
\hline Toplam girdi $\left(\mathrm{MJ} \mathrm{ha}^{-1}\right)$ & Toplam çıktı $\left(\mathrm{MJ} \mathrm{ha}^{-1}\right)$ \\
\hline 16646.61 & 23603.49 \\
\hline
\end{tabular}


Çizelge $10^{\prime}$ da denemelerin birinci ve ikinci yılında elde edilen ortalama çıtı girdi değerleri verilmiştir. Bu değerlere göre 1. ve 2. yılın ortalama toplam girdisi $16544 \mathrm{MJ} \mathrm{ha}^{-1}$, ortalama toplam çıktısı ise $23437.35 \mathrm{MJ} \mathrm{ha}^{-1}$ olarak belirlenmiştir.

Çizelge 10- Denemelerin birinci ve ikinci yılında elde edilen ortalama çıktı girdi değerleri

Table 10- Output and input values obtained from the average of the second year and first year of trials

\begin{tabular}{ccc}
\hline Yıllar & $\begin{array}{c}\text { Toplam girdi } \\
\left(M^{\prime} h a^{-1}\right)\end{array}$ & $\begin{array}{c}\text { Toplam çıtı } \\
\left(M^{-1} h^{-1}\right)\end{array}$ \\
\hline 1. y1l & 16441.39 & 23271.20 \\
2. y1l & 16646.61 & 23603.49 \\
\hline Ortalama & 16544.00 & 23437.35 \\
\hline
\end{tabular}

Isparta yöresinde gül tarımı yapılan işletmelerde, iki yıllık tarla denemesi sonuçlarına göre ortalama enerji girdileri içerisinde özellikle en yüksek değeri mekanizasyon yerine kullanılan insan işgücü enerjisinin aldığ 1 görülmekte olup bunu yakıt yağ enerji girdisinin izlediği görülmektedir. Bunun nedeni mekanizasyon girdilerinin kullanımında insan işgücünün kullanılması ve 30 gün süren hasatta mekanizasyon olmadığı için hasatta mekanizasyon yerine tamamen insan işgücünün kullanılması neticesidir. Traktör ve makine yapım enerjileri ise düşük oranlarda kalmıştır. Birinci ve ikinci yılın ortalama genel enerji girdileri içerisinde insan işgücü enerjisi, gübre enerji girdisinden sonra ikinci sırada yer almaktadır. Bu durum yağlık gül yetiştiriciliğinde özellikle hasat mekanizasyonu uygulamalarının yetersiz olmasından kaynaklanmaktadır. Özellikle hasatta insan işgücünün yoğun kullanılması hasat mekanizasyonunun gelişmesinin gerekli olduğuna işaret etmektedir. Benzer şekilde Weiss (1997), gül hasadında insan işgücünün düşürülmesi ve mekanizasyon girdisinin artırılması gerektiğini, bunun içinde mekanik toplayıcıların kullanılması gerektiğini bildirmektedir.

Isparta bölgesindeki gül üretiminde yakıtyağ enerji girdisi, 1. ve 2. yılın ortalama genel enerji girdileri içerisinde \% 6.56 seviyelerinde bulunmuştur. $\mathrm{Bu}$ sonuçlar gül tarımında mekanizasyon uygulamalarının sınırlı olduğunu, toprak işleme ve ilaçlama dışında mekanizasyon uygulamalarının bulunmadığını göstermektedir. Birinci ve ikinci yılın ortalama genel enerji girdileri içerisinde, tarımsal savaş ilaçlarının enerji girdisi $\% 4.40$ seviyelerinde belirlenmiştir. Çiftlik gübresi girdisi ise genel enerji girdileri içerisinde \% 3.02 seviyelerindedir. $\mathrm{Bu}$ oran kimyasal gübre girdisine oranla yaklaşık 20 kat daha azdır. Acatay (1968), bir hektara 25 ton hayvan gübresi verildiği zaman, alınan gül veriminin 10 ton ha ${ }^{-1}$ ' 1 üstüne çıktığını belirlemiştir.

Çizelge 4 ve 8 'e göre, araştırma bölgesinde traktör ve makine yapım enerjisinin düşük olması, üretimde kullanılan makinelerin yetersizliğini, başka bir ifade ile gül tarımında mekanizasyonun yetersiz olduğu fikrini desteklemektedir. Enerji girdileri içerisinde, sulama enerjisi girdisinin oranı \% 0.38 olarak belirlenmiştir. Bu durumun işletmelerin ortalama gül verimine $\left(6.81\right.$ ton $\left.\mathrm{ha}^{-1}\right)$ yansıdığını, başka bir ifade ile sulama yapan işletmelerin sayısının artırılması gerektiğini belirtebiliriz. İki yıllık gül üretiminde, çıktı/girdi oranı ortalama 1.42 olarak belirlenmiştir. Denemelerin birinci ve ikinci yılının VZA değerleri tablosu Çizelge 11'de verilmiştir.

Çizelge 11- Denemelerin birinci ve ikinci yılının VZA değerleri

Table 11-Data envelopment analysis values of the first and second trials

\begin{tabular}{ccc}
\hline İşletme no & $1 . y l l$ & $2 . y l l$ \\
\hline 1 & 0.984 & 0.561 \\
2 & 1.000 & 0.649 \\
3 & 1.000 & 1.000 \\
4 & 1.000 & 1.000 \\
5 & 1.000 & 1.000 \\
6 & 1.000 & 1.000 \\
7 & 1.000 & 0.047 \\
8 & 1.000 & 1.000 \\
9 & 1.000 & 1.000 \\
10 & 0.909 & 0.181 \\
11 & 1.000 & 1.000 \\
12 & 1.000 & 1.000 \\
13 & 1.000 & 1.000 \\
14 & 1.000 & 1.000 \\
15 & 1.000 & 1.000 \\
\hline
\end{tabular}


Karar birimlerinin her biri için 0 ile 1 arasında değişen etkinlik değerleri hesaplanır. Etkinlik değerleri 1' e eşit olan karar birimleri etkin olarak kabul edilir ve etkinlik sınırlarını oluşturur (ADİ 2013). Birinci yıl çıktı/girdi oranlarına yapılan VZA etkinlik analizi sonuçlarına göre, 1. işletmenin (0.984) ve 10. işletmenin (0.909) girdileri etkin olarak kullanmadığı belirlenmiştir. 2. yıl çıktı/ girdi oranlarına yapılan VZA etkinlik analizi sonuçlarına göre ise 1. (0.561), 2. (0.649), 7. (0.047) ve 10. (0.181) işletmelerin girdileri etkin olarak kullanmadığı belirlenmiştir. Bu analiz sonuçlarını, 1., 2. ve 7. işletmelerin toprak işleme ve kimyasal gübrelerdeki enerji girdilerinin yüksek olmasına, 10. işletmede ise ürün veriminin düşüklügüune bağlayabiliriz. Başka bir ifade ile toprak işleme sayısının ve kimyasal gübre kullanımının azaltılmasını ve çiftlik gübresinin kullanılmasının artırılmasını önerebiliriz.

\section{Sonuçlar}

$\mathrm{Bu}$ araştırmada yöredeki yağ gülü üretimindeki enerji bilançoları belirlenmiştir. Birinci ve ikinci yılın ortalama gübre girdi enerjisinin yüksek olması, üreticilerin toprak analizlerini yaptırmadan uyguladıkları gübrelemeye dayanmaktadır. Gübreye alternatif olarak organik madde yönünden zengin olan gül posasının gübrelemede kullanılma olanaklarının geliştirilmesi yönündeki çalışmaları (Acatay 1968; Özcan 1998) planlanmalı ve desteklenmelidir. Erdal ve Aydemir (2003), gülyağ üretiminden sonra arda kalan posaların gübre olarak kullanıldığında (20-40 ton ha ${ }^{-1}$, bitki gelişimi ve topraktaki besin maddesini artırdığı; posanın \% 2.50 oranında 20:20:20 gübresi ve $\% 5$ oranında taze tavuk gübresi ile karıştırıldığında, bitki gelişimi ve topraktaki besin maddesi içeriğini daha da yüksek oranda artırdığını belirlemişlerdir.

Girdienerjileriiçerisindeinsanişgücününyüksekliği, gül hasadında mekanizasyon uygulamalarının yetersiz olmasından kaynaklanmaktadır. Gülün hasat mekanizasyonu üzerine çalışmalar yapılarak hasat makineleri geliştirilmelidir.
Gül verimini artırmak için sulama imkânı olan bölgelerde ve yeni tesis edilen tarlalarda damla sulama sistemleri kurulmalıdır. $\mathrm{Su}$ kaybının önlenmesi amacıyla gül posasından, pomza, diatomit gibi malzemelerden yararlanarak malçlama yapılmalıdır. Böylece yabancı ot, hastalık ve zararlılar ile mücadele ile birlikte mevcut su buharlaşmayacak ve toprakta meydana gelebilecek su kaybı önlenecektir.

Araştırma yapılan işletmelerde ortalama çıktı/ girdi oran 1.42 olarak bulunmuştur. Değerlendirilen sonuçlara göre enerji kullanımı açısından gül üretiminin karlı bir üretim olduğunu söylemek mümkündür. Ancak yaklaşık hektar başına 6.81 ton gül çiçeği hasat edilmesine rağmen bu durum gül üreticilerinin çoğunu memnun etmemektedir.

\section{Teşekkür}

$\mathrm{Bu}$ araştırma Selçuk Üniversitesi BAP tarafından 07201052 proje numarasıyla desteklenmiştir.

\begin{tabular}{|c|c|}
\hline \multicolumn{2}{|c|}{ Kisaltmalar ve Semboller } \\
\hline$V_{g}$ & Gerçek ilerleme hızı, $\mathrm{km} \mathrm{h}^{-1}$ \\
\hline$L$ & Ölçüm uzunluğu, m \\
\hline$t$ & $\begin{array}{l}\text { Ölçüm uzunluğunun alınması için geçen } \\
\text { zamanların aritmetik ortalaması, s }\end{array}$ \\
\hline$A_{i s ̧}$ & İş başarısı, ha $h^{-1}$ \\
\hline$B_{g}$ & Gerçek iş genişliği, m \\
\hline$V_{g}$ & Gerçek ilerleme hızı, $\mathrm{km} \mathrm{h}^{-1}$ \\
\hline$T_{e f}$ & Zamandan yararlanma katsayısı, \% \\
\hline$T_{e s}$ & $\begin{array}{l}\text { Esas zaman (makinenin tarlada çalıştığı gerçek } \\
\text { süre), h }\end{array}$ \\
\hline$T_{d}$ & Dönme zamanı (dönüşlerde geçen zaman), h \\
\hline$T_{k}$ & $\begin{array}{l}\text { Kayıp zaman (çalışma sırasında oluşan arızalar- } \\
\text { dan kaynaklanan zaman), h }\end{array}$ \\
\hline$M_{p}$ & Makine yapım (imalat) enerjisi, $\mathrm{MJ} \mathrm{kg}^{-1}$ \\
\hline$M_{\ddot{u}}$ & Malzeme üretim enerjisi, MJ \\
\hline$F$ & Fabrika yapım enerjisi, MJ \\
\hline$Y_{d}$ & Yedek parça enerjisi, MJ \\
\hline$M_{p e}$ & Makine enerjisi, $\mathrm{MJ} \mathrm{ha}^{-1}$ \\
\hline$G$ & Makinenin kütlesi, kg \\
\hline$T$ & Makinenin kullanım ömrü, $\mathrm{h}$ \\
\hline
\end{tabular}




\section{Kaynaklar}

Acaroğlu M(1998). Energy from biomass and applications. University of Selcuk Graduate of Natural and Applied Sciences, Textbook, Konya

Acaroğlu M (2004). Miscanthus X Giganteus'un Orta Anadolu-Konya şartlarında yetiştirilmesi ve enerji bilançosunun belirlenmesi. II. Ulusal Ege Enerji Sempozyumu ve Sergisi, Dumlupınar Üniversitesi, 2628 Mayıs, Kütahya, s. 358-362

Acatay A (1968). Gül ve Gülyağı. İstanbul Üniversitesi Orman Fakültesi, Orman Entolomojisi ve Koruma Kürsüsü Profesörü, İstanbul

ADİ (2013). A-D İstatistik. Available: http://adistatistik. com/blog/veri-zarflama-analizi-vza-nedir-nasilyapilir.html

AOAC (1999). Official methods of analysis of AOAC international. 16th ed., 5th rev. Method 930, 15, The Association, Gaithersburg, MD

Coelli T (1996). A guide to DEAP version 2.10. A data envelopment analysis (computer) program, CEPA working paper 96/08. Dept Econometrics, Univ. New England, Arm dale, Australia

Coelli T, Rahman S \& Thirtle C (2002). Technical, allocative, cost and scale efficiencies in Bangladesh rice cultivation: A Non-parametric Approach, Journal of Agricultural Economics 53(3): 607-626

Calışır S (2004). The evaluation of performance and energy usage in submersible deep well irrigation pumping plants. AMA-Agricultural Mechanization in Asia, Africa and Latin America 38(1): 9-17

Çiçek A \& Erkan O (1996). Tarım ekonomisinde araştırma ve örnekleme yöntemi. Gaziosmanpaşa Üniversitesi Ziraat Fakültesi Yayınları, No: 12, Tokat

Dinçer H (1976). Tarım işletmelerinde makine kullanma masrafları. Ankara Üniversitesi Ziraat Fakültesi, Zirai Kuvvet Makineleri Kürsüsü, Ankara

El Saleh Y (2000). Suriye ve Türkiye'de mercimek ve nohut hasadında mekanizasyon olanaklarının belirlenmesi üzerine bir araştırma. Doktora tezi, Çukurova Üniversitesi Fen Bilimleri Enstitüsü (Yayımlanmamış), Adana

Erdal İ \& Aydemir O (2003). Gül posasının doğrudan ve zenginleştirilmiş formunun tarımda kullanılabilme olanaklar1, Süleyman Demirel Üniversitesi Fen Bilimleri Enstitüsü Dergisi 7(1): 20-26
Farrell M J (1957). The measurement of productive efficiency. Journal of Royal Statistical Society 120(3): 253-281

Gezer, İ, Acaroğlu M \& Haciseferoğulları H (2003). Use of energy and labour in apricot agriculture in Turkey. Biomass and Bioenergy 24: 215 - 219

Göktürk B (1999). Kuru soğanın hasada yönelik bazı özelliklerinin saptanması, kazıcı bıçaklı tip hasat makinesinin geliştirilmesi ve diğer hasat yöntemleri ile karşılaştırılması üzerinde bir araştırma. Doktora tezi, Trakya Üniversitesi Fen Bilimleri Enstitüsü (Yayımlanmamış), Tekirdağ

Güzel E (1986). Çukurova bölgesinde yerfıstığının söküm ve harmanlanmasının mekanizasyonu ve bitkinin mekanizasyona yönelik özelliklerinin saptanması üzerine bir araştırma. Türkiye Zirai Donatım Kurumu Mesleki Yayınları, Yayın No: 47, Ankara

Haciseferoğulları H, Acaroğlu M \& Gezer I (2003). Determination of the energy balance of the sugar beet plant. Energy Sources 25(1): 15-22

Heyland K U \& Solansky S (1979). Energieeinsatz und energieumsetzung im bereich der pflanzenproduktion. Ber. Landw. 195: 15-30

İGEME (2003). Available: http:// www.igeme.gov.tr

Kaltschmitt M \& Reinhardt A (1997). Nachwachsende energieträger grundlagen, verfahren ökologische bilanzierung. Vieweg Verlag Braunschweig, Wiesbaden

Kıneci S (2005). Gülyağı eldesinde verim arttırıcı yeni tekniklerin araştırılması. Yüksek lisans tezi, Süleyman Demirel Üniversitesi Fen Bilimleri Enstitüsü (Yayımlanmamış), Isparta

Mandal K G, Saha K P, Ghosh P K, Hati K M \& Bandyopadhyay K K (2002). Bioenergy and economic analysis of soybean-based crop production systems in central India. Biomass and Bioenergy 23(5): 337-345

Önal İ \& Tozan M (1986). Sanayi tipi domates yetiştiriciliğinde alternatif üretim sistemlerinin işgücü gereksinmeleri ve enerji bilançosu. Tarımsal Mekanizasyon 10. Ulusal Kongresi, Adana, s. 216228

Özcan M T (1986). Mercimek hasat ve harman yöntemlerinin iş verimi, kalitesi, enerji tüketimi ve maliyet yönünden karşılaştırılması ve uygun bir hasat makinesi geliştirilmesi üzerinde araştırmalar. Türkiye Zirai Donatım Kurumu Yayınları, Yayın No: 46, Ankara 
Özcan Ö (1998). Isparta ili ve çevresinde gül tarımı ve Türkiye ekonomisine katkısı. Yüksek lisans tezi, Marmara Üniversitesi Sosyal Bilimler Enstitüsü (Yayımlanmamış), İstanbul

Shreve R N, Joseph A \& Brink J R (1985). Kimyasal proses endüstrileri-2. (Çeviren: Çataltaş A İ), İnkılap Kitabevi, İstanbul

Singh M K, Pal S K, Thakur R \& Verma U N (1997). Energy input-output relationship of cropping systems. The Indian Journal of Agricultural Sciences 67(6): 262

Singh J M (2002). On farm energy use pattern in different cropping systems in Haryana, Hindistan. Master thesis, International Institute of Management University of Flensburg, Germany

Sonmete M H (2006). Fasulyenin hasat-harman mekanizasyonu ve geliştirme olanakları. Doktora tezi, Selçuk Üniversitesi Fen Bilimleri Enstitüsü (Yayımlanmamış), Konya

TBMM (2006). Available: http:// www.tbmm.gov.tr/ tutanak/donem 22

Weiss E A (1997). Essential oil crops. Cab International Oxon, UK and Newyork, NY

Yıldız M U, Hacıseferoğulları H, Acaroğlu M, Çalışır S \& Gezer İ (2006). Konya bölgesinde kabak çekirdeği üretiminde enerji bilançosunun belirlenmesi. Tarımsal Mekanizasyon 23. Ulusal Kongresi, 6-8 Eylül, Çanakkale, s. 287-291

Yılmaz Ö (1991). Isparta ve yöresinde yetiştirilen güllerin (Rosa damascena Mill.) bazı özelliklerinin saptanması üzerine bir inceleme. Yüksek lisans tezi, Uludağ Üniversitesi Fen Bilimleri Enstitüsü (Yayımlanmamış), Bursa 